\title{
CHS 828 Inhibits Neuroblastoma Growth in Mice Alone and in Combination with Antiangiogenic Drugs
}

\author{
ÅSA SVENSSON, ULRIKA BÄCKMAN, ELIN JONSSON, ROLF LARSSON, AND \\ ROLF CHRISTOFFERSON \\ Department of Medical Cell Biology, Uppsala University [A.S., U.B., R.C.]; Division of Clinical \\ Pharmacology, University Hospital [E.J., R.L.]; and Department of Surgical Sciences, Children's \\ Hospital, Uppsala University [R.C.], Uppsala, Sweden
}

\begin{abstract}
CHS 828 is a new chemotherapeutic drug, a pyridyl cyanoguanidine. CHS 828 has low toxicity and lacks known patterns of multidrug resistance. Here we report that oral, daily treatment with CHS 828 reduced the growth of SH-SY5Y human neuroblastoma tumors in male NMRI nu/nu mice by $82 \%$ without apparent toxicity. CHS 828 induced complete tumor regression for at least 5 weeks in four of nine animals (44\%). Combination therapy with CHS 828 and the antiangiogenic drugs TNP-470 or SU5416 decreased neuroblastoma growth by a further 10 and $3 \%$, respectively. Combination therapy induced tumor regression at d 4 with CHS plus TNP and d 6 with CHS plus SU5416, compared with d 14 with CHS 828 alone $(p<0.05)$, and complete tumor regression was seen in nine of 19 animals (47\%). Combination treatment of CHS 828 and TNP-470 decreased the total viable tumor volume by $71 \%$ compared with treatment with
\end{abstract}

\section{ABSTRACT}

CHS 828 alone. Our findings support CHS 828 as a promising new drug in treatment of childhood cancers. Furthermore, they imply efficiency of daily administration of nontoxic doses of chemotherapy, and a possible additive effect when chemotherapy is combined with angiogenesis inhibitors. (Pediatr Res 51: 607611, 2002)

\section{Abbreviations}

VEGF, vascular endothelial growth factor

CgA, chromogranin A

TH, tyrosine hydroxylase

Lv, length of vessels per tumor volume

Sv, surface area of vessels per tumor volume

$\mathbf{V v}$, volume of vessels per tumor volume
Neuroblastoma is one of the most common solid malignant tumors of childhood. The prognosis varies with age at diagnosis, tumor stage, and certain biologic markers. In patients older than $1 \mathrm{y}$ of age with an advanced tumor stage and dismal biologic markers, the outcome remains poor despite aggressive, multimodal therapy; hence, there is a clinical need for new treatment strategies (1).

A new treatment strategy for human solid tumors is antiangiogenic therapy (2). New drugs have been developed that specifically inhibit the formation of new blood vessels in solid tumors, thereby reducing tumor growth and metastasis (3). Two such antiangiogenic drugs in clinical trials are TNP-470, which inhibits endothelial cell proliferation (4), and SU5416, which blocks downstream signaling from VEGF receptor-2, an

Received September 14, 2001; accepted December 19, 2001.

Corresponding and reprint requests: Åsa Svensson, M.Sc., Department of Medical Cell Biology, Box 571, S-751 23 Uppsala, Sweden; e-mail: Asa.Svensson@medcellbiol.uu.se Supported by grants from the Swedish Cancer Society, the Children's Cancer Foundation of Sweden, H R H Crown Princess Lovisa's Association for Child Medical Care, the Gunnar, Arvid and Elisabeth Nilsson Foundation, the Mary Béve Foundation, and the Faculty of Medicine at Uppsala University. important pathway in angiogenesis (5). Experimental data suggest that antiangiogenic therapy potentiates chemotherapy (6).

Chemotherapeutic drugs can exert an antiangiogenic effect if administered in a low dose daily [antiangiogenic scheduling, $(6,7)]$. Cyclophosphamide and vinblastine have been successfully tested in this respect in animal models, but not a new class of chemotherapeutic drugs, the pyridyl cyanoguanidines, such as CHS 828. CHS 828 has shown promising antitumor activity both in vitro and in vivo (8). However, the mechanism of its cytotoxicity is still unclear, and the question of whether CHS 828 has antiangiogenic properties has not been addressed. This study was performed to characterize the antitumor efficacy of CHS 828-given in a daily schedule orally-alone and in combination with one of the antiangiogenic agents TNP-470 or SU5416, in a xenograft model for human neuroblastoma.

\section{METHODS}

Drugs. All substances were suspended in their solvent immediately before injection. CHS 828 [ $N$-(6-chlorophenoxy- 
hexyl)- $N$ '-cyano- $N^{\prime \prime}-4$-pyridylguanidine; Leo Pharmaceutical Products, Ballerup, Denmark] was suspended in peanut oil. TNP-470 (Takeda Chemical Industries Ltd., Osaka, Japan) was suspended in $1 \%$ ethanol and $5 \%$ gum arabic in $0.9 \mathrm{mg} / \mathrm{mL}$ $\mathrm{NaCl}$ solution. SU5416 \{3-[(2,4-dimethylpyrrol-5-yl) methylidenyl]-indolin-2-one; Sugen Inc., South San Francisco, CA, U.S.A.\} was suspended in $0.5 \%$ (wt/vol) carboxy-methylcellulose sodium, $0.9 \%(\mathrm{wt} / \mathrm{vol}) \mathrm{NaCl}, 0.4 \%$ (vol $/ \mathrm{vol}$ ) polysorbate 80 , and $0.9 \%(\mathrm{vol} / \mathrm{vol})$ benzyl alcohol in deionized water to the appropriate concentration.

Cells. SH-SY5Y cells, derived from a poorly differentiated, non-MYCN-amplified human neuroblastoma tumor (9), were used. These cells express VEGF and several other angiogenesis stimulators $(10,11)$. The cells were maintained in Eagle's minimal essential medium (SVA, Uppsala, Sweden) supplemented with $10 \%$ FCS, $1 \mu \mathrm{M}$ L-glutamine, penicillin (100 $\mathrm{U} / \mathrm{mL})$, and streptomycin $(50 \mu \mathrm{g} / \mathrm{mL}$; Sigma Chemical Co., St. Louis, MO, U.S.A.). The cells were grown in humidified air $(95 \%)$ and $5 \% \mathrm{CO}_{2}$ at $37^{\circ} \mathrm{C}$.

Animals. Seventy-five male NMRI nu/nu mice (B \& M, Ry, Denmark) were used for xenografting at an age of $6 \mathrm{wk}$ (body weight, $25-30 \mathrm{~g}$ ). The animals were housed at a temperature of $24^{\circ} \mathrm{C}$, with a 12 -h light, 12 -h dark cycle. They were fed $\mathrm{ad}$ libitum with water and food pellets. All handling of the animals was carried out under aseptic conditions. The animal weight and general appearance were recorded every other day throughout the experiment. The experiment was approved by the regional ethics committee for animal research.

Xenografting. Subconfluent cells in triple-chamber culture flasks (Nunc, Roskilde, Denmark) were harvested by adding trypsin and $0.02 \%$ EDTA for $10 \mathrm{~min}$. The cells were spun down and resuspended in medium to $150 \times 10^{6}$ cells $/ \mathrm{mL}$. The recipient mice were anesthetized with $2 \%$ Fluothane (Zeneca Ltd., Macclesfield, U.K.) supplemented with $50 \% \mathrm{~N}_{2} \mathrm{O}$ in oxygen, and $0.2 \mathrm{~mL}$ of the cell suspension was injected s.c. in the right hind leg. Care was taken to avoid leakage from the puncture site and not to inject intramuscularly.

Measurement of tumor volume and administration of drugs. Tumor volume measurement began when the tumor became palpable (approximately $0.1 \mathrm{~mL}$ ) and was then repeated every second day. The animal was anesthetized, and the longest diameter of the tumor and the width perpendicular to it were measured with a caliper. Tumor volume was then calculated as length $\times$ width $^{2} \times 0.44$. When a tumor reached a volume of $0.3 \mathrm{~mL}$, the treatment began. Animals with a tumor volume less than $0.3 \mathrm{~mL}, 4 \mathrm{wk}$ after injection of tumor cells, were excluded from the study. At the time when the animals reached this volume, they were randomized into treatment groups in the following order: control $(n=10)$, CHS 828 only $(n=9)$, TNP-470 only $(n=10)$, SU5416 only $(n=9)$, CHS 828 plus TNP-470 $(n=10)$, and CHS 828 plus SU5416 $(n=$ 9). All animals received treatment within 2 to $4 \mathrm{wk}$ after injection of tumor cells. Control animals were given vehicle without active drug. CHS 828 at a dose of $20 \mathrm{mg} / \mathrm{kg}$ was given daily by oral gavage with a 1.2 -mm-diameter umbilical vessel catheter (Argyle, Sherwood Medical, St. Louis, MO, U.S.A.). SU5416 and TNP-470 at doses of $50 \mathrm{mg} / \mathrm{kg}$ and $15-30 \mathrm{mg} / \mathrm{kg}$, respectively (see below for doses of TNP-470), were injected every second day s.c. in the neck.

Perfusion fixation and autopsy. Animals were anesthetized by an i.p. injection of $25 \mathrm{mg} / \mathrm{kg}$ of 2,2,2-tribromoethanol (Sigma Chemical Co.) in 2.5\% 2-methyl-2-butanol (Sigma Chemical Co.) in $0.9 \mathrm{mg} / \mathrm{mL} \mathrm{NaCl}$ solution. A cannula was inserted in the thoracic aorta, and the animal was perfusionfixed with $4 \%$ paraformaldehyde in $1.47 \mathrm{mg} / \mathrm{mL} \mathrm{NaH}_{2} \mathrm{PO} 4$. $\mathrm{H}_{2} \mathrm{O}, 12.62 \mathrm{mg} / \mathrm{mL} \mathrm{Na}_{2} \mathrm{HPO} 4 \cdot 2 \mathrm{H}_{2} \mathrm{O}$, and $4.09 \mathrm{mg} / \mathrm{mL} \mathrm{NaCl}$ in distilled $\mathrm{H}_{2} \mathrm{O}$ (Millonig's buffer, $\mathrm{pH} 7.4,37^{\circ} \mathrm{C}$ ). The internal organs were examined for macroscopic metastases.

Blood analyses. Venous blood was drawn from the right atrium with a heparinized syringe before the perfusion fixation. The heparinized blood was put on ice and spun within $30 \mathrm{~min}$ at $2000 \times g$ for $20 \mathrm{~min}$. The plasma was then removed and stored at $-20^{\circ} \mathrm{C}$.

Determination of CHS 828 concentrations was performed by Leo Pharmaceuticals, by an HPLC method with UV detection at $277 \mathrm{~nm}(12)$.

Tissue analyses. The paraformaldehyde-fixed tumors were dehydrated and embedded in paraffin. Tissue sections, $3 \mu \mathrm{m}$ thick, were cut and put on diaminoalkyl-silane treated glass slides, dehydrated, and stained immunohistochemically.

Cell proliferation was detected by Ki-67 nuclear antigen staining, which recognizes all cell cycle phases except $\mathrm{G}_{0}$. The tissue sections were blocked in $0.3 \%$ hydrogen peroxide for 20 min, microwave treated $(750 \mathrm{~W})$ for $2 \times 5 \mathrm{~min}$ in citrate buffer (21 $\mathrm{mg} / \mathrm{mL} \mathrm{C}_{6} \mathrm{H}_{8} \mathrm{O}_{7} \cdot \mathrm{H}_{2} \mathrm{O}$ in distilled $\mathrm{H}_{2} \mathrm{O}$, pH 6.0), and blocked for $10 \mathrm{~min}$ in $1 \%$ BSA in PBS consisting of $2 \mathrm{mg} / \mathrm{mL}$ $\mathrm{KH}_{2} \mathrm{PO}_{4}, 2 \mathrm{mg} / \mathrm{mL} \mathrm{KCl}, 80 \mathrm{mg} / \mathrm{mL} \mathrm{NaCl}$, and $28.8 \mathrm{mg} / \mathrm{mL}$ $\mathrm{Na}_{2} \mathrm{HPO}_{4} \cdot 2 \mathrm{H}_{2} \mathrm{O}$ in distilled $\mathrm{H}_{2} \mathrm{O}$. The primary antibody (MIB 1, monoclonal mouse anti-human Ki-67 nuclear antigen, Dianova, Hamburg, Germany) was applied at 1:100 for $1 \mathrm{~h}$ at room temperature. The secondary antibody (polyclonal, biotinylated rabbit anti-mouse immunoglobulins, E 354, Dako A/S, Glostrup, Denmark), 1:200, was applied for $30 \mathrm{~min}$. For detection, ABComplex/HRP (K 355, Dako A/S), 1:200, was applied for $30 \mathrm{~min}$. This was followed by development with diaminobenzidine tetrahydrochloride (Sigma Chemical Co.) and counterstaining with Harris's hematoxylin. Sections of human breast carcinoma served as a positive control, and omission of the primary antibody as a negative control. All antibodies were diluted in 1\% BSA in PBS.

Staining specific for neuroendocrine and adrenergic cells, i.e. neuroblastoma cells, was performed by $\mathrm{CgA}$ and $\mathrm{TH}$ immunohistochemistry (13). Tissue sections were blocked in $0.3 \%$ hydrogen peroxide for $20 \mathrm{~min}$ and microwave treated $(750 \mathrm{~W})$ for $2 \times 5 \mathrm{~min}$ in citrate buffer for TH staining only. This was followed by blocking in $1 \%$ BSA and $10 \%$ normal rabbit serum for $30 \mathrm{~min}$. The primary antibody (monoclonal mouse anti-human CgA, No. 1199 021, or monoclonal rabbit anti-TH, No. 1017381; Boehringer Mannheim GmbH, Mannheim, Germany) was applied at 1:500 for $30 \mathrm{~min}$ or 1:80 overnight, respectively. The secondary antibody (polyclonal, biotinylated rabbit anti-mouse immunoglobulins, E 354, Dako A/S) was applied at 1:80 and 1:200, respectively, for $30 \mathrm{~min}$. For detection, ABComplex/HRP (K 355, Dako A/S), 1:200 for $\mathrm{CgA}$ and 1:100 for $\mathrm{TH}$, was applied for $30 \mathrm{~min}$, followed by 


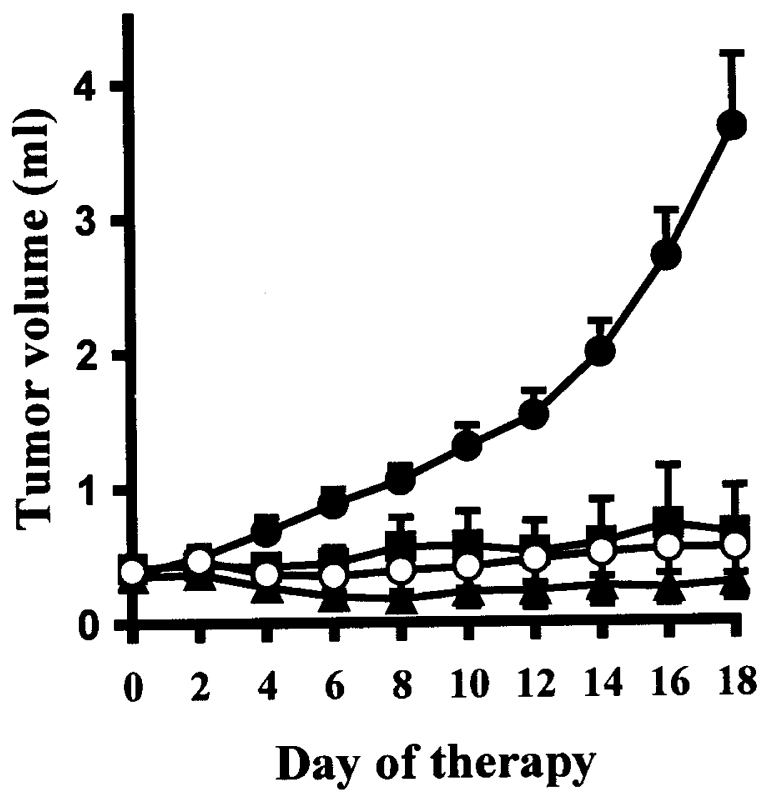

Figure 1. Neuroblastoma growth in nude mice: control $(n=10 ; \bullet)$, CHS 828 $(n=9 ; \square)$, CHS $828+\operatorname{TNP}-470(n=10 ; \mathbf{\Delta})$, and CHS $828+\operatorname{SU} 5416(n$ $=9 ; \circ)$. Results are expressed as mean \pm SEM.

development with diaminobenzidine tetrahydrochloride and counterstaining with hematoxylin. Sections from human jejunum served as a positive control for $\mathrm{CgA}$, and human adrenal medulla for TH. Omission of the primary antibody served as a negative control. All antibodies were diluted in $1 \%$ BSA in PBS.

Apoptosis was determined by terminal deoxynucleotidyl transferase-mediated dUTP nick-end labeling assay (14). After deparaffinization, the sections were digested with proteinase $\mathrm{K}$ (Sigma Chemical Co., $20 \mu \mathrm{g} / \mathrm{mL}$ ) for $50 \mathrm{~min}$. After four washes in distilled water and blocking in $2.0 \%$ hydrogen peroxide in PBS, the Apoptag kit (Oncor, Gaithersburg, MD, U.S.A.) was applied according to the manufacturer's instructions. As a positive control, DNase I was added (20 min at $37^{\circ} \mathrm{C}$ ) after blocking in hydrogen peroxidase, thus producing DNA breaks in virtually all cells. Replacement of TdT with water served as a negative control. The slides were counterstained with hematoxylin.

Vascular counts were performed on hematoxylin and eosinstained tissue sections. The blood vessels are visible as punched out holes in stained sections after perfusion fixation, and hence no specific endothelial cell marker was necessary. $\mathrm{Lv}, \mathrm{Sv}$, and $\mathrm{Vv}$ were calculated as previously described (13).

Stereological quantifications. All sections were quantified by one observer in a blinded fashion. Structures were counted at $\times 400$ with an eyepiece grid (506800, Leica, Singapore, Singapore $)$ of $10 \times 10$ squares $(0.25 \times 0.25 \mathrm{~mm})$. The grid was placed at random at the upper left corner of a section, and then systematically advanced every 1 to $3 \mathrm{~mm}$ (depending on the tumor size) in both directions with use of the microscope goniometer stage. Morphologic variables from at least 15 grids were quantified for each tumor. Areas with hemorrhage and apoptotic or necrotic cells were considered as nonviable and were excluded from analysis of other variables (13), but were used for calculation of the viable tissue fraction. The estimate of viable tissue fraction was used to calculate the total viable tumor volume (viable tissue fraction $\times$ tumor volume). The fractions of Ki-67-positive and terminal deoxynucleotidyl transferase-mediated dUTP nick-end labeling-positive tumor cells were determined among 2,000 cells in each section.

Statistical methods. Data were processed in GraphPad Prism for Windows (GraphPad Software Inc, San Diego, CA, U.S.A.). Differences among groups in tumor growth and tissue variables were analyzed with the Kruskal-Wallis test and Dunn's multiple comparison test. Differences for which $p<$ 0.05 were considered statistically significant.

\section{RESULTS}

Neuroblastoma growth. The tumor growth rate was significantly lower in all CHS 828 treatment groups than in the control animals (Fig. 1). This difference was statistically evident as early as $\mathrm{d} 4$ in the combination treatment group CHS $828+$ TNP-470 and d 6 in the CHS $828+$ SU5416 group, but not until d 14 in the group treated with CHS 828 alone. Tumor growth was not significantly decreased by treatment with any of the antiangiogenic drugs when given alone (data not shown).

The experiment was terminated when the control animals' tumors reached a volume of $4.0 \mathrm{~mL}$ (approximately $10 \%$ of body weight). The mean tumor volume of treated animals divided by the mean tumor volume of control animals (the T/C ratio) on d 18 was 0.18 for CHS 828 alone, 0.15 for CHS 828 + SU5416, and 0.08 for CHS 828 + TNP-470. In each treatment group, some animals exhibited complete tumor regression at $\mathrm{d}$ 18: four of nine (44\%) in the group given CHS 828 alone, four of nine $(44 \%)$ in the CHS $828+$ SU5416

Table 1. Overview of experiments

\begin{tabular}{|c|c|c|c|c|}
\hline Variable & Controls & CHS 828 & $\begin{array}{c}\text { CHS } 828+ \\
\text { SU5416 }\end{array}$ & CHS $828+$ TNP-470 \\
\hline$n$ & 10 & 9 & 9 & 10 \\
\hline Dosage (mg/kg) & 0 & 20 daily & 20 daily +50 qod & 20 daily $+15-30$ qod \\
\hline Total viable tumor volume $(\mathrm{mL}) \S$ & $2.60 \pm 1.36$ & $1.43 \pm 0.32$ & $0.87 \pm 0.32 \dagger$ & $0.41 \pm 0.30 \ddagger$ \\
\hline $\mathrm{T} / \mathrm{C}$ & 1.0 & 0.18 & 0.15 & 0.080 \\
\hline Complete tumor regression & $0 / 10$ & $4 / 9$ & $4 / 9$ & $5 / 10$ \\
\hline
\end{tabular}

Mean \pm SD. $* p \leq 0.05, \dagger p \leq 0.01$, and $\ddagger p \leq 0.001$, Kruskal-Wallis test.

$\S$ Calculated on controls $(n=9)$, CHS $828(n=3)$, CHS $828+$ SU5416 $(n=3)$, and CHS $828+$ TNP-470 $(n=4)$. Comparison with controls or combination treatment groups compared with CHS 828 only indicated significance for CHS $828+$ TNP-470 $(p<0.05)$.

$\mathrm{T} / \mathrm{C}$, treatment to control ratio for tumor volume on $\mathrm{d} 18$. 
group, and five of $10(50 \%)$ in the CHS $828+$ TNP-470 group (Table 1).

All animals gained weight and appeared healthy during the experiment, apart from the CHS $828+$ TNP-470 group, which exhibited moderate weight loss. In this group, therefore, half the dose of TNP-470 (i.e. $15 \mathrm{mg} / \mathrm{kg}$ every other day) was given. The tumor volume at $\mathrm{d} 18$ in the combination groups did not differ significantly from that in the group treated with CHS 828 alone. In animals from each CHS 828 treatment group, eight animals in all, that exhibited complete tumor regression, treatment was withheld for more than $40 \mathrm{~d}$ without regrowth of tumors.

Plasma CHS 828 concentrations. Plasma CHS 828 concentrations were $0.94 \pm 0.68 \mu \mathrm{g} / \mathrm{mL}$ in 12 of 20 analyzed samples; eight samples had concentrations below the detection limit of $0.1 \mu \mathrm{g} / \mathrm{mL}$.

Angiogenesis. Owing to the unforeseen tumor regression, the tissue variables could be quantified only in three to four tumors from each CHS 828 treatment group. Hence, lack of statistical significance may be owing to the small sample size. However, a consistent reduction of angiogenesis, as reflected in a lower $\mathrm{Lv}, \mathrm{Vv}$, and $\mathrm{Sv}$ than in controls, was observed in most treatment groups (Table 2). The mean tumor blood vessel diameter $(46 \pm 17 \mu \mathrm{m})$ was similar in all groups, indicating that the methodology was reproducible.

Tumor cell proliferation. The fraction of proliferating neuroblastoma cells was not significantly reduced in any of the treatment groups (Table 3).

Tumor cell apoptosis. The fraction of apoptotic neuroblastoma cells was increased (by 1.05- to 2.2-fold) in all treatment groups except the group given CHS 828 alone, in which it was paradoxically decreased. These differences did not reach significance (Table 3).

All tumors exhibited cells staining positively for $\mathrm{CgA}$ and $\mathrm{TH}$, confirming that the tumors were of neuroblastoma origin. There was no difference in the amount of labeled cells among the treatment groups.

Viable tumor tissue fraction and total viable tumor volume. Antiangiogenic treatment alone decreased the viable tumor tissue fraction, although the decrease was not statistically significant. The total viable tumor volume was significantly decreased by $71 \%(p<0.05)$ in animals treated with CHS 828 plus TNP-470 compared with treatment with CHS 828 alone (Table 1).

Table 2. Quantification of tumor angiogenesis on 18 of therapy

\begin{tabular}{lcccc}
\hline & & & CHS 828 + & CHS 828 + \\
\multicolumn{1}{c}{ Variable } & Controls & CHS 828 & SU5416 & TNP-470 \\
\hline$n$ & 9 & 3 & 3 & 3 \\
Lv $\left(\mathrm{mm}^{-2}\right)$ & $115 \pm 45$ & $68 \pm 44$ & $103 \pm 45$ & $40 \pm 31$ \\
$\quad$ Difference $(\%)$ & & -41 & -10 & -65 \\
Vv $\left(10^{-3}\right)$ & $0.17 \pm 0.09$ & $0.09 \pm 0.06$ & $0.12 \pm 0.03$ & $0.061 \pm 0.02$ \\
$\quad$ Difference (\%) & & -48 & -29 & -64 \\
Sv (mm $\left.{ }^{-1}\right)$ & $4.2 \pm 1.4$ & $2.8 \pm 1.2$ & $4.2 \pm 0.78$ & $2.4 \pm 0.86$ \\
$\quad$ Difference $(\%)$ & & -33 & 0 & -43 \\
\hline
\end{tabular}

Mean \pm SD. For definitions of Lv, Vv, and Sv, see Wassberg et al. (13). Differences were not significant ( $p<0.05$, Kruskal-Wallis test).
Table 3. Quantification of tumor dynamics on 18 of therapy

\begin{tabular}{lcccc}
\hline \multicolumn{1}{c}{ Variable } & Control & CHS 828 & $\begin{array}{c}\text { CHS 828 } \\
+ \text { SU5416 }\end{array}$ & $\begin{array}{c}\text { CHS 828 } \\
+ \\
\text { TNP-470 }\end{array}$ \\
\hline$n$ & 9 & 3 & 3 & 3 \\
Viable tissue (\%) & $66 \pm 24$ & $86 \pm 24$ & $75 \pm 34$ & $67 \pm 47$ \\
$\quad$ Difference & & 30 & 14 & 1.5 \\
Proliferating cells (\%) & $4.4 \pm 3.2$ & $4.0 \pm 3.9$ & $2.4 \pm 0.88$ & $3.6 \pm 1.1$ \\
$\quad$ Difference & & -9.1 & -52 & -18 \\
Apoptotic cells (\%) & $6.3 \pm 5.7$ & $3.1 \pm 1.6$ & $6.6 \pm 5.4$ & $14 \pm 12$ \\
$\quad$ Difference & & -51 & 4.8 & 110 \\
\hline
\end{tabular}

Mean \pm SD. Differences were not significant $(p<0.05$, Kruskal-Wallis test).

\section{DISCUSSION}

There is now accumulating clinical and experimental evidence that solid tumor growth is angiogenesis dependent, in that an increase in the tumor cell population has to be preceded by an increase in nutritive blood vessels (2). This hypothesis is supported by the findings that rapidly growing and metastasizing human tumors exhibit more blood vessels than do less aggressive tumors $(15,16)$ and that circulating levels of angiogenic peptides are elevated in patients with disseminated disease (17-19). Neuroblastoma has a high expression of angiogenesis stimulators (10). Furthermore, correlation of angiogenesis with poor outcome in neuroblastoma patients has been shown (20). Thus, antiangiogenic therapy may improve the long-term outcome in patients with this tumor. The tumor vasculature may be targeted therapeutically, either by specific inhibitors of endothelial proliferation and migration, or by cytotoxic drugs given at a low dose continuously (antiangiogenic scheduling), or by a combination of these approaches (6, $7,21,22)$. SH-SY5Y neuroblastoma cells xenografted to nude mice will inevitably kill the animals within $3 \mathrm{wk}$ after tumor take. We have shown here that a new chemotherapeutic drug, CHS 828, administered daily, efficiently inhibits neuroblastoma growth in our xenograft model. When CHS 828 is combined with two specific antiangiogenic drugs, tumor regression occurs more rapidly and decreases the total viable tumor volume of the tumors.

CHS 828 is a pyridyl cyanoguanidine with potent antitumor activity both in vitro and in vivo. It shows low correlation with the activity patterns of known anticancer drugs, and of known patterns of multidrug resistance (8). Interestingly, CHS 828 has structural similarities to the catecholamine precursor metaiodobenzylguanidine, which is known to accumulate in neuroblastomas and is used for imaging and radiotherapy $(23,24)$. We are currently investigating whether it is CHS 828 as such or an antiangiogenic schedule that reduces neuroblastoma growth. Also, we are addressing the issue of cyclic therapy, i.e. the question of whether regressed tumors regrow, and if so, whether they are still sensitive to CHS 828 therapy. Yet another question at issue is whether the antiangiogenic scheduling can be more effective if the drug is given continuously by an implantable osmotic minipump.

TNP-470 is a synthetic analog to the fungal antibiotic fumagillin, and inhibits endothelial cell migration and proliferation $(4,25-27)$. It has been shown to inhibit tumor growth and 
metastasis in both murine tumors and human xenografts in vivo, but not to induce tumor regression. TNP-470 has been shown to reduce angiogenesis and to increase tumor necrosis by increased differentiation and apoptosis in experimental neuroblastoma [agonal differentiation (13)]. TNP-470 alone in mice reduces angiogenesis consistent with our previous results in rats (22) but with a lower treatment to control ratio of 0.69 (unpublished data). TNP-470 in combination with CHS 828 induced complete tumor regression in five of 10 animals compared with four of nine animals with CHS 828 treatment alone. TNP-470 in combination with CHS 828 gave an earlier tumor regression and decreased the total viable tumor tissue volume. Thus TNP-470 increases the efficacy of CHS 828 treatment.

SU5416 is an angiogenesis inhibitor currently in phase 3 clinical trials. SU5416 inhibits VEGF signaling by acting as a VEGF receptor-2 tyrosine kinase inhibitor. It is an ATP competitive inhibitor of the kinase (5). A variety of human tumors express VEGF and its receptors. VEGF is considered to be one of the key mediators of angiogenesis (28). Our experimental neuroblastomas express VEGF on both the mRNA and protein levels (unpublished data). When SU5416 was combined with CHS 828, complete tumor regression was seen in four of nine animals, but did not decrease the total viable tumor volume, although an earlier tumor regression than for CHS 828 treatment alone was seen when compared with controls.

We conclude that the new therapeutic drug CHS 828 alone, as well as in combination with antiangiogenic drugs, is a potent inhibitor of experimental neuroblastoma growth in vivo in doses not causing systemic toxicity. The additional facts that our study and previous investigations of CHS 828 have shown no patterns of multidrug resistance and low toxicity make it a promising new drug in treatment of childhood cancers.

Acknowledgments. The authors thank Barbro Einarsson and Helena Hermelin for providing excellent technical assistance. We also thank Leo Pharmaceutical Products, Sugen Inc., and Takeda Chemical Industries Ltd. for kindly providing us with the drugs, and Leo Pharmaceuticals for measuring the CHS 828 drug concentrations.

\section{REFERENCES}

1. Berthold F, Hero B 2000 Neuroblastoma: current drug therapy recommendations as part of the total treatment approach. Drugs 59:1261-1277

2. Carmeliet P, Jain RK 2000 Angiogenesis in cancer and other diseases. Nature 407:249-257

3. Deplanque G, Harris AL 2000 Anti-angiogenic agents: clinical trial design and therapies in development. Eur J Cancer 36:1713-1724

4. Kusaka M, Sudo K, Matsutani E, Kozai Y, Marui S, Fujita T, Ingber D, Folkman J 1994 Cytostatic inhibition of endothelial cell growth by the angiogenesis inhibitor TNP-470 (AGM-1470). Br J Cancer 69:212-216
5. Fong TA, Shawver LK, Sun L, Tang C, App H, Powell TJ, Kim YH, Schreck R, Wang X, Risau W, Ullrich A, Hirth KP, McMahon G 1999 SU5416 is a potent and selective inhibitor of the vascular endothelial growth factor receptor (Flk-1/KDR) that inhibits tyrosine kinase catalysis, tumor vascularization, and growth of multiple tumor types. Cancer Res 59:99-106

6. Klement G, Baruchel S, Rak J, Man S, Clark K, Hicklin DJ, Bohlen P, Kerbel RS 2000 Continuous low-dose therapy with vinblastine and VEGF receptor-2 antibody induces sustained tumor regression without overt toxicity. J Clin Invest 105:R15-R24

7. Browder T, Butterfield CE, Kraling BM, Shi B, Marshall B, O'Reilly MS, Folkman J 2000 Antiangiogenic scheduling of chemotherapy improves efficacy against experimental drug-resistant cancer. Cancer Res 60:1878-1886

8. Hjarnaa PJ, Jonsson E, Latini S, Dhar S, Larsson R, Bramm E, Skov T, Binderup L 1999 CHS 828, a novel pyridyl cyanoguanidine with potent antitumor activity in vitro and in vivo. Cancer Res 59:5751-5757

9. Biedler JL, Roffler-Tarlov S, Schachner M, Freedman LS 1978 Multiple neurotransmitter synthesis by human neuroblastoma cell lines and clones. Cancer Res 38:37513757

10. Eggert A, Ikegaki N, Kwiatkowski J, Zhao H, Brodeur GM, Himelstein BP 2000 High-level expression of angiogenic factors is associated with advanced tumor stage in human neuroblastomas. Clin Cancer Res 6:1900-1908

11. Meister B, Grunebach F, Bautz F, Brugger W, Fink FM, Kanz L, Mohle R 1999 Expression of vascular endothelial growth factor (VEGF) and its receptors in human neuroblastoma. Eur J Cancer 35:445-449

12. Jonsson E, Friberg LE, Karlsson MO, Hassan SB, Freijs A, Hansen K, Larsson R 2000 Determination of drug effect on tumour cells, host animal toxicity and drug pharmacokinetics in a hollow-fibre model in rats. Cancer Chemother Pharmacol 46:493-500

13. Wassberg E, Hedborg F, Sköldenberg EG, Stridsberg M, Christofferson RH 1999 Inhibition of angiogenesis induces chromaffin differentiation and apoptosis in neuroblastoma. Am J Pathol 154:395-403

14. Gold R, Schmied M, Giegerich G, Breitschopf H, Hartung HP, Toyka KV, Lassmann H 1994 Differentiation between cellular apoptosis and necrosis by the combined use of in situ tailing and nick translation techniques. Lab Invest 71:219-225

15. Brawer MK, Deering RE, Brown M, Preston SD, Bigler SA 1994 Predictors of pathologic stage in prostatic carcinoma: the role of neovascularity. Cancer 73:678687

16. Choi HJ, Hyun MS, Jung GJ, Kim SS, Hong SH 1998 Tumor angiogenesis as a prognostic predictor in colorectal carcinoma with special reference to mode of metastasis and recurrence. Oncology 55:575-581

17. Dirix LY, Vermeulen PB, Pawinski A, Prove A, Benoy I, De Pooter C, Martin M, Van Oosterom AT 1997 Elevated levels of the angiogenic cytokines basic fibroblast growth factor and vascular endothelial growth factor in sera of cancer patients. Br J Cancer 76:238-243

18. Nguyen M, Watanabe H, Budson AE, Richie JP, Hayes DF, Folkman J 1994 Elevated levels of an angiogenic peptide, basic fibroblast growth factor, in the urine of patients with a wide spectrum of cancers. J Natl Cancer Inst 86:356-361

19. Nguyen M 1997 Angiogenic factors as tumor markers. Invest New Drugs 15:29-37

20. Meitar D, Crawford SE, Rademaker AW, Cohn SL 1996 Tumor angiogenesis correlates with metastatic disease, $\mathrm{N}-m y c$ amplification, and poor outcome in human neuroblastoma. J Clin Oncol 14:405-414

21. Kakeji Y, Teicher BA 1997 Preclinical studies of the combination of angiogenic inhibitors with cytotoxic agents. Invest New Drugs 15:39-48

22. Wassberg E, Pahlman S, Westlin JE, Christofferson R 1997 The angiogenesis inhibitor TNP-470 reduces the growth rate of human neuroblastoma in nude rats. Pediatr Res 41:327-333

23. Montaldo PG, Lanciotti M, Casalaro A, Cornaglia-Ferraris P, Ponzoni M 1991 Accumulation of m-iodobenzylguanidine by neuroblastoma cells results from independent uptake and storage mechanisms. Cancer Res 51:4342-4346

24. Troncone L, Rufini V $1997{ }^{131}$ I-MIBG therapy of neural crest tumours (review). Anticancer Res 17:1823-1831

25. Antoine N, Greimers R, De Roanne C, Kusaka M, Heinen E, Simar LJ, Castronovo V 1994 AGM-1470, a potent angiogenesis inhibitor, prevents the entry of normal but not transformed endothelial cells into the $\mathrm{G}_{1}$ phase of the cell cycle. Cancer Res 54:2073-2076

26. Ingber D, Fujita T, Kishimoto S, Sudo K, Kanamaru T, Brem H, Folkman J 1990 Synthetic analogues of fumagillin that inhibit angiogenesis and suppress tumour growth. Nature 348:555-557

27. Kusaka M, Sudo K, Fujita T, Marui S, Itoh F, Ingber D, Folkman J 1991 Potent anti-angiogenic action of AGM-1470: comparison to the fumagillin parent. Biochem Biophys Res Commun 174:1070-1076

28. Ferrara N, Alitalo K 1999 Clinical applications of angiogenic growth factors and their inhibitors. Nat Med 5:1359-1364 